\title{
Fault zone exploitation in geothermal reservoirs: Production optimization, permeability evolution and induced seismicity
}

\author{
Kingsley Anyim ${ }^{1,2}$, Quan $\operatorname{Gan}^{1 \oplus *}$ \\ ${ }^{1}$ School of Geosciences, University of Aberdeen, Aberdeen, AB24 3UE, UK \\ ${ }^{2}$ Department of Earth and Environmental Sciences, University of Minesota, Minneapolis, MN 55455, USA
}

\section{Keywords:}

Fault reactivation

geothermal reservoirs

production optimization

permeability evolution

induced seismicity

Cited as:

Anyim, K., Gan, Q. Fault zone

exploitation in geothermal reservoirs:

Production optimization, permeability

evolution and induced seismicity.

Advances in Geo-Energy Research, 2020,

4(1): 1-12, doi: 10.26804/ager.2020.01.01.

\begin{abstract}
:
This study employs a coupled thermal-hydrological-mechanical model to investigate the permeability evolution and fault reactivation of a critically stressed fault in geothermal reservoir. The fracture permeability sensitivity analysis for permeabilities of the fault damage zone that hydro-mechanical processes have dominating control on permeability evolution and the associated timing of slip on the fault plane for high fracture permeability. The mode of thermal sweep in the reservoir is dominated by advection, as the high fracture permeability permitted higher velocity of fluid flow. For the condition of low fracture permeability, heat transfer process has pronounced control on permeability evolution and timing of slip due to heat conduction process. With reduction in fluid flow and hydromechanical effects, heat transfer in the reservoir is dominated by heat conduction, as the temperature difference between the fault zone and the country rock becomes negligible. For the intermediate fracture permeabilities, the induced thermal unloading due to conduction could prompt the onset of failure. Changing the locations of the injection well along the fault zone shows that shear failure on the fault/fracture plane occurs earlier for lower stress state and vice versa. The evolutions of production rate and power generation are also influenced by the stress state at the injection and production wells. The elevated pore pressures in the fault zone due to fluid injection causes distributed seismicity on the fault/fracture planes which all have moment magnitudes that are below 2.5 .
\end{abstract}

\section{Introduction}

Geothermal resources from hot dry rock (HDR) can be exploited in the form of enhanced (engineered) geothermal systems (EGS) (Cummings and Nunn, 1978; Tester et al., 1989; Duchane and Brown, 2002). Unlike in hydrothermal systems where mobile water occurs naturally, most of the world geothermal resource is locked up in hot rock at depth but dry (without mobile water) (Duchane and Brown, 2002). The HDR is characterized by low natural porosity and permeability and so need to be fractured artificially to create engineered (enhanced) geothermal reservoirs (Tester et al., 1989). The EGS employs a process known as hydraulic stimulation that involves the enhancement of natural rock permeability or the creation of permeability in the hot dry rock by injecting cold water under pressure (Tester et al., 1989; Duchane and Brown, 2002). The hydraulic stimulation entails the re-opening of mineralized natural joints and fissures, and not the rupturing of competent rock (Duchane and Brown, 2002; Tester et al., 2006). The injected water extracts the heat from the crystalline HDR as it circulates and a second well (the withdrawal well) is then drilled into the engineered geothermal reservoir to produce the hot water.

The exploitation of geothermal energy especially the EGS remains challenging because of the technical difficulties involved in its development as well as the implications like induced seismicity. Researchers have employed models to understand the thermo-hydro-mechanical-chemical (THMC) processes in enhanced geothermal reservoirs (e.g., Rutqvist et al., 2002; Fomin et al., 2004; Taron et al., 2009; Taron and Elsworth, 2009, 2010; Gan and Elsworth, 2014a, 2014b; Gan and Elsworth, 2016a, 2016b; Pandey et al., 2017; Salimzadeh et al., 2018; Ijeje et al., 2019). These models prove to be useful in strengthening the understanding of geothermal reservoir

${ }^{*}$ Corresponding author.

E-mail address: anyim001@umn.edu (K. Anyim); gan.quan@abdn.ac.uk (Q. Gan). 
processes, ranging from fluid flow, permeability evolution, induced seismicity, heat transfer, to production optimization.

The issue of induced seismicity in enhanced geothermal reservoirs is of great concern both to the scientific and political community (Ellsworth, 2013). Cold fluid injection in enhanced geothermal reservoirs is critical in evaluating the fault reactivation and induced seismicity (Cappa and Rutqvist, 2010; Gan and Elsworth, 2014a). Injection of large amount of water into geothermal reservoirs increases the pore pressure and the potential in causing failure on fault planes (Hubert and Rubey, 1959; Cappa and Rutqvist, 2010; Ellsworth, 2013; Levandowski et al., 2018; Scholz, 2019). This slip tendency is defined based on the Mohr-Coulomb failure criterion. Slip occurs when the pore pressure increases high enough to cause the shear stress component to exceed frictional resistance (Hubert and Rubey, 1959; Scholz, 2019), defined as,

$$
t=\mu_{s}\left(\sigma_{n}-p\right)+C=\mu_{s} \sigma_{n e f f}+C
$$

where $\tau$ represents the shear stress, $\mu_{s}$ is the coefficient of friction, $\sigma_{n}$ represents the normal stress, $p$ is the pore pressure, $\sigma_{n e f f}$ is the effective normal stress, and the $C$ represents the cohesion (Hubert and Rubey, 1959; Gan and Elsworth, 2014a; Scholz, 2019). Assuming cohesion on the existing fault plane is negligible (e.g., Zoback, 2010; Gan and Elsworth, 2014a; McNamara et al., 2015; Levandoski et al., 2018). Apart from hydromechanical processes, fault reactivation can also be caused by thermal processes in the geothermal reservoir (Rutqvist and Oldenburg, 2007; Gan and Elsworth, 2014a, 2014b). Injection of cold water in EGS has the potential to cause perturbation of thermal stress regimes in geothermal reservoirs, and has been linked to a latestage thermal drawdown-induced fault reactivation (Gan and Elsworth, 2014a, 2014b).

THM modelling has also been found useful in understanding heat transfer processes vis-à-vis fracture/fault parameters in geothermal reservoirs (Li et al., 2013; Pandey et al., 2017). Though the rock matrix stores most of the thermal energy in the EGS, fractures and fault zones play a key role in engineered geothermal systems as they provide pathways for fluid and heat transfer (Pruess, 1983). Improvement in our understanding of heat transfer models in geothermal reservoirs and fractured media is crucial as it affects the amount of heat energy extracted from the geothermal reservoir (Pruess, 1983; Li et al., 2013).

Responsible exploitation of renewable energy from EGS requires effective production optimization and minimizes the risk of hazards like induced seismicity. This study aims at exploring the thermo-hydro-mechanical processes by utilizing fault zone as conduit to exploit geothermal energy.

The permeability profile of the fault zone has a great influence on fluid flow (Caine et al., 1996; Evans et al., 1997), especially in geothermal reservoirs where the fault zone is exploited. It is therefore important to understand the architecture of the fault zone in order to understand their HM properties (Faulkner et al., 2003). The structure of the fault zone basically comprises of three components: the fault core, the damage zone, and the host rock or protolith (Caine et al., 1996; Mitchell and Faulkner, 2009).

The fault core commonly is comprised by narrow clay-rich layer that is poorly consolidated or a zone of reduced grain size with or without mineralization (Chester and Logan, 1987; Caine et al., 1996; Boutareaud et al., 2008). The damage zone is characterized by higher fracture density and deformation (Chester and Logan, 1987). The protolith (or the host rock) is characterized by regional structures and are unaffected by the fault-associated deformation (Chester and Logan, 1987; Caine et al., 1996; Boutareaud et al., 2008). The fault core and the damage zone represent two distinct units within the fault zone in terms of structure and fluid flow (Caine et al., 1996). The permeability profile across the fault zone (see Fig. 1) is represented by a high permeability in the damage zone, a low permeability in the fault core which constitutes a flow barrier, and an intermediate permeability in the protolith (Evans et al., 1997; Faulkner et al., 2003; Boutareaud et al., 2008).

\section{Model set-up}

This study employed the coupled Thermal-HydrologicMechanical (THM) model TOUGHREACT-FLAC3D for simulating processes in geothermal reservoirs within fractured porous media (Taron and Elsworth, 2009; Taron et al., 2009). There is data interpolation between the TOUGHREACT central nodes and the FLAC3D corner nodes. A separate code known as the interpolation module (see Fig. 2) is responsible for linking FLAC3D and TOUGHREACT data which includes models for permeability evolution, models for porosity change, poroelasticity, and fluid compressibility. The interpolation module is a Fortran 90 executable and can access data outputs from both FLAC3D and TOUGHREACT (Taron and Elsworth, 2009). The data interpolation enables the computation of effective stresses from pore pressures which can then be used with a suitable constitutive model for permeability change to investigate fracture aperture evolution and concomitant fracture permeability evolution (Gan and Elsworth, 2014a).

The setup of the model is such as to enable the investigation of fault zone exploitation in geothermal reservoirs. An initially stable fault with angle of internal friction equal to $28^{\circ}$ was emplaced in the model surrounded by host rock (Byerlee, 1978). The exploitation strategy of the fault zone is here investigated by defining circulating fluids along permeable damage zones. The permeability of the fault core zones were kept constant throughout this study, as the fracture permeability of the fault zone is concentrated in the damage zone of the fault, the prescribed permeability for surrounding non-faulted host rock is given at $10^{-19} \mathrm{~m}^{2}$ to stand for the tight granite rocks. Consequently, the permeability anisotropy is limited within fault damage zones, especially along the strike direction. The calculation of permeability for the faulted blocks will also incorporate the normal stress acting and orientation of the weaken plane. Production optimization vis-à-vis the locations of the injection and production wells along the fault is investigated. This study also investigates the permeability evolution within the fault damage zone and modes of thermal sweep in the geothermal reservoir. The permeability evolution is 


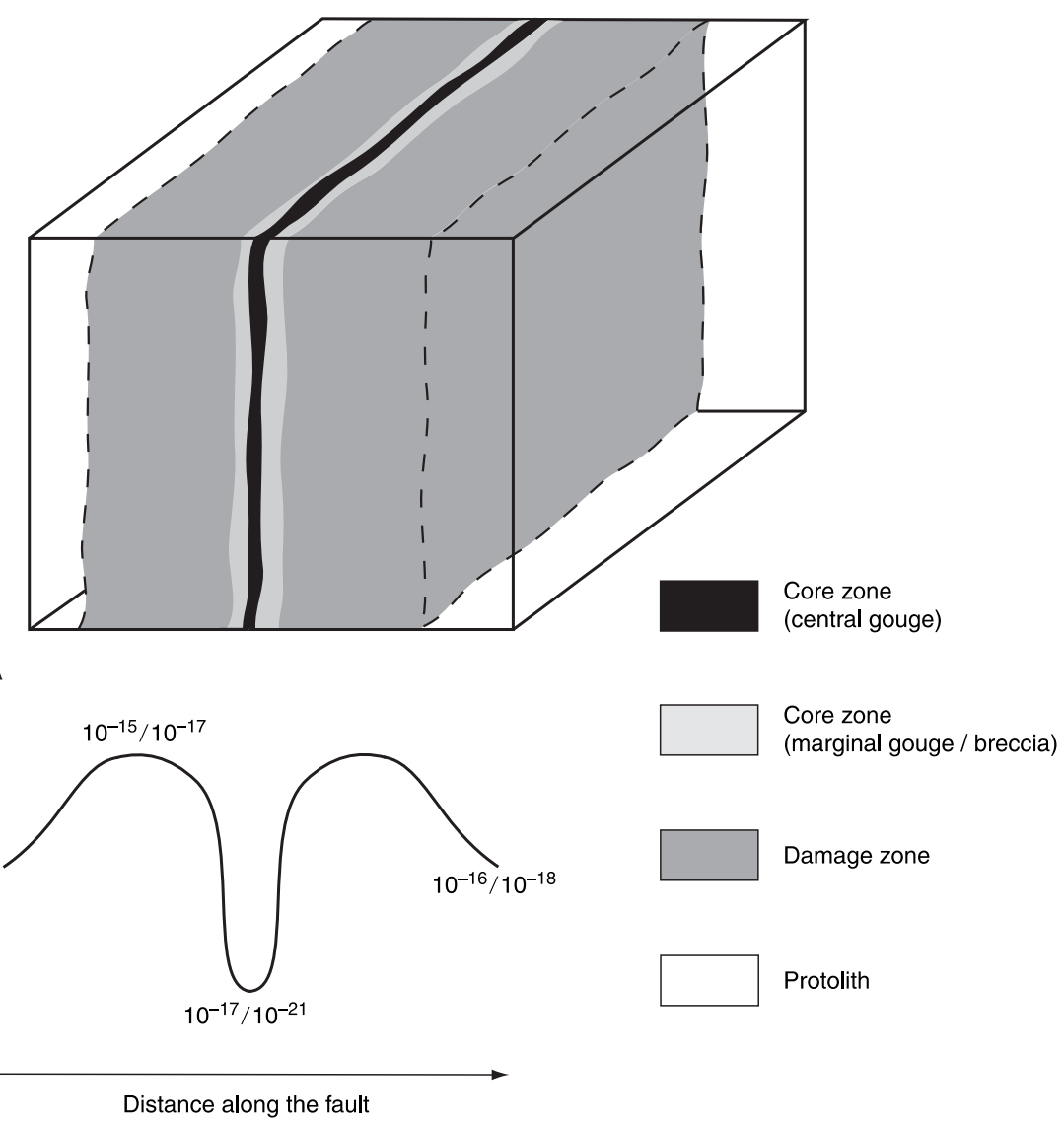

Fig. 1. Typical fault zone permeability profile (Boutareaud et al., 2008). The fault damage zone has the highest permeability within the fault zone due to its highest fracture density.

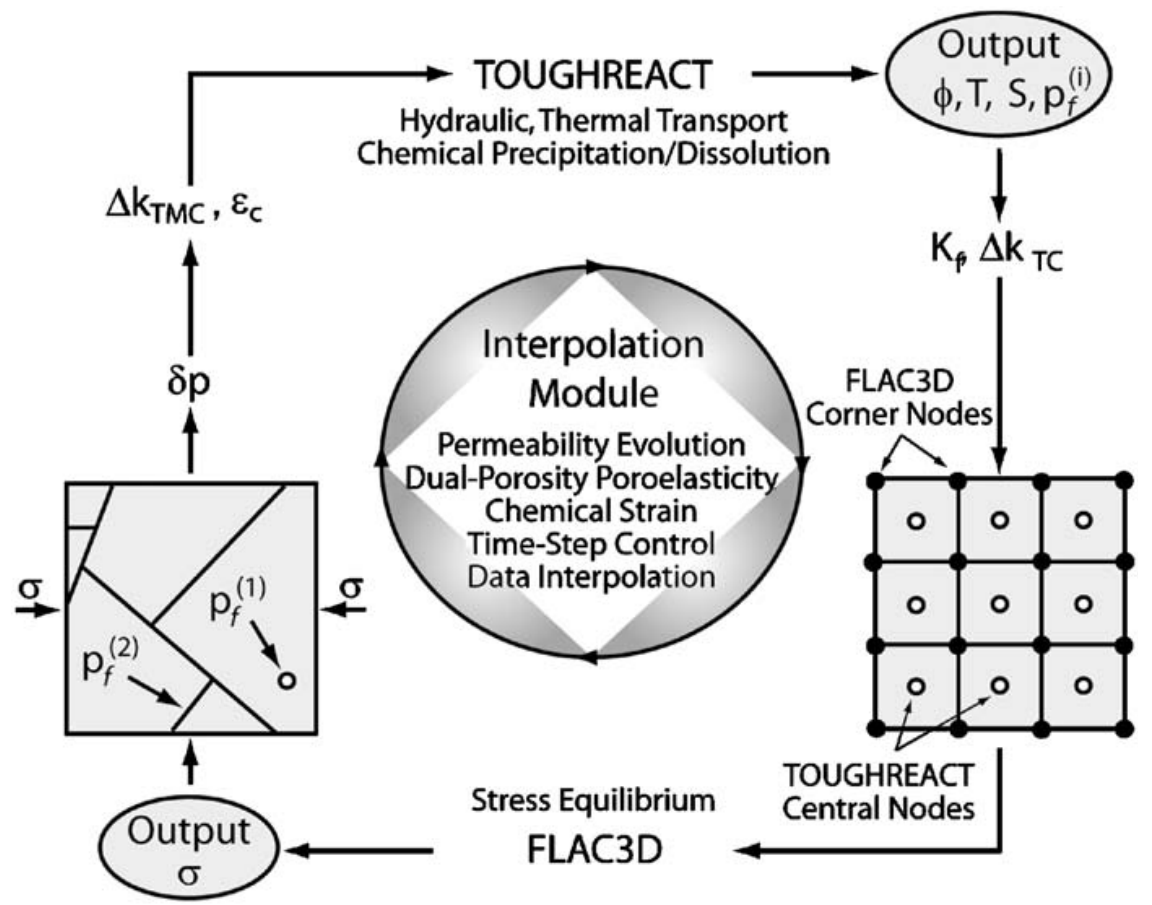

Fig. 2. Coupling between TOUGHREACT and FLAC3D (Taron et al., 2009). 
Table 1. Material properties and values used in the simulation.

\begin{tabular}{llll}
\hline Parameters & Damage Zone & Core Zone & Rock Matrix \\
\hline Permeability $\left(\mathrm{m}^{2}\right)$ & $10^{-16}$ to $10^{-12}$ & $10^{-17}$ & $10^{-16}$ \\
Young's modulus $(\mathrm{GPa})$ & 2.52 & 2.52 & 25.2 \\
Shear modulus $(\mathrm{GPa})$ & 1.03 & 1.03 & 10.3 \\
Poisson's ratio & 0.22 & 0.22 & 0.22 \\
Friction angle $\left({ }^{\circ}\right)$ & 28 & 28 & 45 \\
Thermal expansion coefficient, $1 /{ }^{\circ} \mathrm{C}$ & & & $1.2 \mathrm{e}-5$ \\
Formation heat conductivity, $\mathrm{W} / \mathrm{m}^{\circ} \mathrm{C}$ & & & 2.51 \\
Rock specific heat, $\mathrm{J} / \mathrm{kg}^{\circ} \mathrm{C}$ & & & 918 \\
Fracture porosity & 0.3 & 0.3 & \\
\hline
\end{tabular}

dependent upon the fault zone fracture aperture evolution. The fracture spacing is kept constant at $10 \mathrm{~m}$ throughout the study. Induced seismicity and slip tendency along the fault zone due to fluid injection was examined with the fluid injection rate kept constant at $10 \mathrm{~kg} / \mathrm{s}$.

\subsection{Constitutive model for permeability change}

The permeability model employed in this study allow fracture aperture-dependent permeability evolution, due to the variation of effective stress state. According to the cubic law for fluid flow in fractured media (Witherspoon et al., 1980), the fracture aperture-dependent permeability is given by:

$$
k=\frac{b^{3}}{12 s}
$$

where $b$ represents the fracture aperture, $s$ represents the fracture spacing, and $k$ represents the fracture permeability. There are various constitutive models to depict the behaviour of fracture aperture under applied stress. In this study, the nonlinear fracture stiffness model for fracture aperture-dependent permeability change is employed. The non-linear fracture stiffness model is preferred because of its ability to depict fracture stiffening as the fracture is closed due to applied stress (Min et al., 2009). This non-linear model empirically defines fracture aperture growth under the influence of applied effective normal stress $\sigma$ and the observed fracture stiffness $\alpha$ (Rutqvist et al., 2002; Min et al., 2009; Taron and Elsworth, 2009; Taron et al., 2009) as:

$$
b_{m}=b_{m r}+\left(b_{m o}-b_{m r}\right) \exp \left(-\alpha\left(\sigma-\sigma_{o}\right)\right)
$$

where $b_{m}$ represents the hydraulic fracture aperture as a result of mechanical stress effect alone, $b_{m o}$ represents the fracture aperture under no mechanical stress effect, $b_{m r}$ represents the residual aperture under mechanical stress effect only, $\sigma_{o}$ represents the effective stress at zero deformation (Taron et al., 2009), and $\alpha$ represents the non-linear fracture stiffness. The model assumes that the mechanical aperture $(b)$ in Eq. (2) is approximately equal to the hydraulic aperture $\left(b_{m}\right)$ in Eq. (3), i.e. $b \sim b_{m}$ (Gan and Elsworth, 2014a). The mechanical stress effect controls the evolution of the fracture aperture which in turn controls the evolution of the fracture permeability.

\subsection{Model description}

The geometry of the geothermal reservoir used in this study is represented in Fig. 3a, with dimensions of $600 \mathrm{~m}$, $15 \mathrm{~m}$, and $600 \mathrm{~m}$ in $x, y$, and $z$ axis respectively, representing a pseudo 3-D doublet. A strike-slip fault of length $424 \mathrm{~m}$ and breadth $2 \mathrm{~m}$ with dip orientation of $45^{\circ}$ is emplaced in the model with an initial uniform reservoir temperature of $200{ }^{\circ} \mathrm{C}$ and initial pore pressure of $13.8 \mathrm{MPa}$. The fault is separated into the fault damage zone and the fault core. The damage zone represents the fluid pathway in this study because of its high fracture permeability and hence the locations of both the injection and production wells. The fault zone is characterized by preponderance of joint model to depict the fault zone's elastic-plastic tendencies. The initial stresses (see Fig. 3) are 27.3 MPa and 45.5 MPa representing the minimum and maximum boundary stresses respectively. The minimum stress acts in the E-W direction while the maximum stress acts in the N-S direction. Other material properties and values used in the model are listed in Table 1.

The fault has an initial angle of internal friction of $28^{\circ}$, and the mechanical simulation adopts a plastic friction strainsoftening constitutive model, by assuming the decrease in friction angle with development of plastic deformation in fault joints (Fig. 3b). The rock matrix is assigned with a classical Mohr Coulomb model with an internal friction angle of $45^{\circ}$.

\subsection{Fault plane initial stability}

The initial stability of the fault plane was examined with respect to the model's initial mechanical conditions and values. The coefficient of the fault's friction was used to examine the fault plane initial stability (Jaeger et al., 2007). The fault plane stability and slip tendency was then evaluated using the relation (Rutqvist and Oldenburg, 2007; Gan and Elsworth, 2014a):

$$
\frac{\sigma_{1}^{\prime}}{\sigma_{3}^{\prime}}=\frac{\sigma_{1}-\alpha p}{\sigma_{3}-\alpha p} \leq Q=\left[\left(\mu_{s}{ }^{2}+1\right)^{1 / 2}+\mu_{s}\right]^{2}
$$




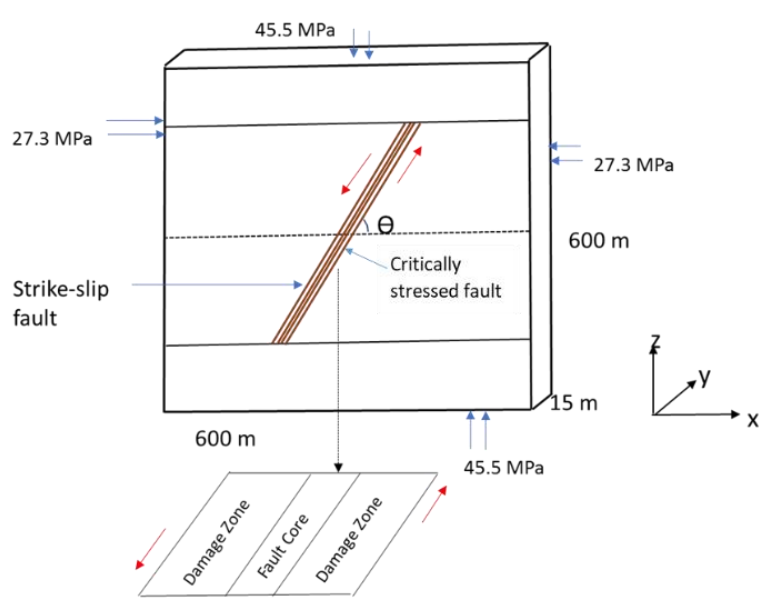

(a)

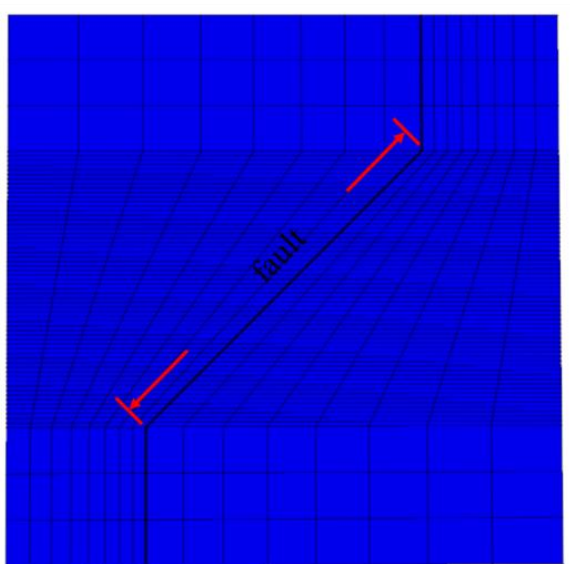

(b)

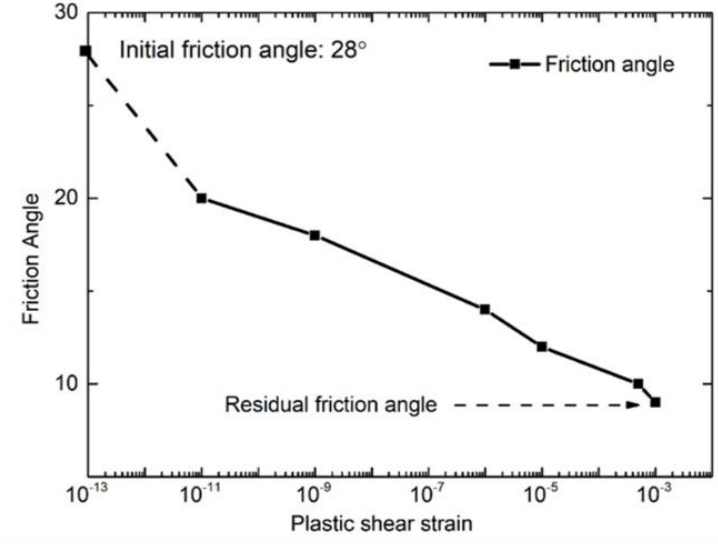

(c)

Fig. 3. (a) Geometry of the enhanced geothermal reservoir used in this study with the fault architecture with initial stress boundary conditions, (b) associated mesh grid implemented in the FLAC3D, (c) adopted friction weakening table with development of plasti shear strain.

where $\sigma_{1}^{\prime}$ is the maximum principal effective stress, $\sigma_{3}^{\prime}$ is the minimum principal effective stress, $\alpha$ is the Biot coefficient, $p$ is the initial pore pressure and $Q$ is the limiting effective stress ratio, $\mu_{s}$ is the coefficient of friction. The fault plane fails when the ratio $\sigma_{1}^{\prime} / \sigma_{3}^{\prime}$ becomes greater than $Q$. From the model's initial conditions and values, fault friction angle is $28^{\circ}$ so that $\mu_{s}$ is 0.53 , the corresponding value of $Q$ is therefore 2.76. Also, $\sigma_{1}=45.5 \mathrm{MPa}, \sigma_{3}=27.3 \mathrm{MPa}$, initial pressure $=13.8 \mathrm{MPa}, \alpha=1$, so that the ratio $\sigma_{1}^{\prime} / \sigma_{3}^{\prime}=2.35$ which is less than $Q=2.76$. This represents a fault that is stable but critically stressed. The cohesion was also set to zero.

\section{Results interpretation}

\subsection{Permeability evolution}

Permeability sensitivity analysis was carried out within the fault damage zone in order to investigate the THM processes in the fault zone. The permeability evolution is dependent on fracture aperture evolution under stress. The fracture permeability of the damage zone was varied from $10^{-16}$ to $10^{-12} \mathrm{~m}^{2}$, while the fracture spacing is kept constant at $10 \mathrm{~m}$ throughout the study. The stress dependent fracture permeability varies with the onset of shear failure or normal compaction. The fracture permeability evolutions of the five different initial fracture permeabilities $\left(10^{-16}\right.$ to $\left.10^{-12} \mathrm{~m}^{2}\right)$ are shown in Fig. 4, which shows the fracture permeability is dynamic as it continually evolves in response to the evolution of the hydraulic fracture aperture under the effect of mechanical stress. Both thermal and HM conditions including shear failure on fault/fracture plane have contributed to the evolution of the fracture permeability. The timing of slip (see Fig. 4) for the five different permeabilities have been controlled by the interplay of both thermal and HM conditions. As the injection rate for the five scenarios are kept constant at $10 \mathrm{~kg} / \mathrm{s}$, the variation of permeability design has direct impact in the gradient of pressure built-up based on the Darcy's Law, if the thermal effect is excluded. The high permeability condition $\left(k=10^{-12} \mathrm{~m}^{2}\right)$ could have the smallest pressure built-up velocity, based on the Darcy's equation, comparing to other lower permeability cases,

$$
q=\frac{k A}{\mu B} \frac{d P}{d L}
$$

where $q$ is the volumetric injection rate, $k$ is the permeability of medium, $A$ is cross section area of fluids flowing in the channel, $B$ is formation volume factor, $\mu$ is the viscosity of fluid, and $d P / d L$ is the pressure gradient between the 


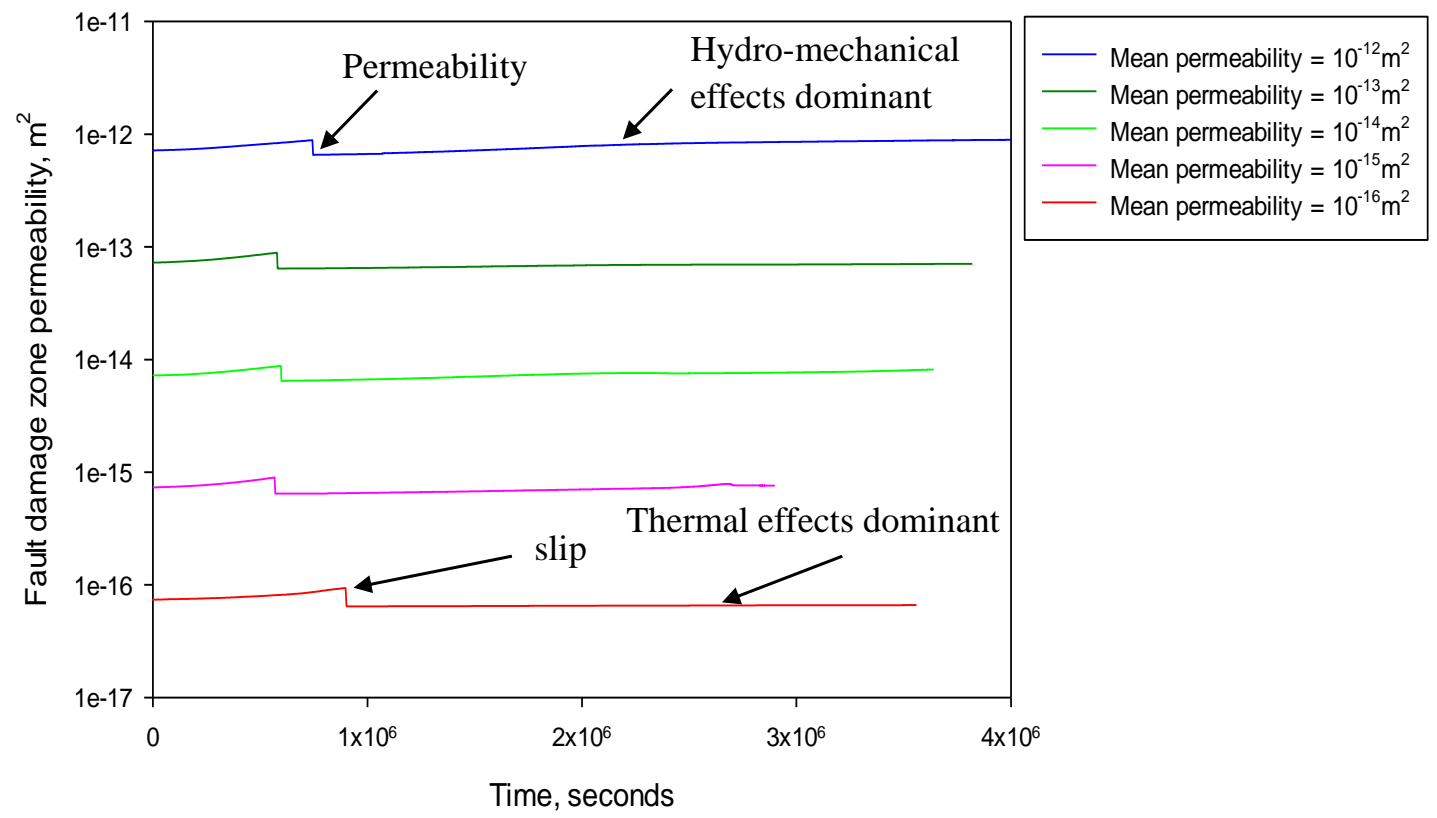

Fig. 4. Fracture permeability evolution for initial permeabilities ranging from $10^{-16}$ to $10^{-12} \mathrm{~m}^{2}$.

injection and target point. Due to the relative high velocity of fluids in fracture channels, it will leave small residence time for fluids to pick up heat as a mode of heat advection. Consequently, the major impact in changing stress state is dominated by the HM process. When the permeability is gradually reduced to $10^{-15} \mathrm{~m}^{2}$, the timing for slip onset is gradually decreased, there are two potential explanation. The first hypothesis is the increase of pressure gradient, when the fault permeability is reduced at constant injection rate condition, it reduced the required timing to slip. Secondly, the localized heat transfer by conduction could change the stress state of fault by thermal unloading (Gan and Elsworth, 2014a). Therefore HM effects have dominant control on the evolution of the higher permeabilities $\left(10^{-12} \mathrm{~m}^{2}\right)$ while the gradual pronounced thermal effects plays on the evolution of the stress state under lower permeabilities $\left(10^{-15}-10^{-12} \mathrm{~m}^{2}\right)$. The slip timing result for the permeability $\left(k=10^{-16} \mathrm{~m}^{2}\right)$ is reversely higher than the other condition. This observation could partly be explained due to the potential increasing communication between fault and the host surrounding rocks, which led to a small gradient of pressure built-up, as the fault and host non-faulted rocks have similar permeability magnitude.

The evolution of the Coulomb stress ratio (Fig. 5) indicates the time of slip on the fault plane for the different permeabilities. The angle of internal friction of the fault damage zone used in the simulation is $28^{\circ}$ which corresponds to a value of 0.53 as the coefficient of static friction (i.e. Tangent of $28^{\circ}$ ). Slip or shear failure on the fault/fracture planes therefore occurs when the Coulomb stress ratio equals or exceeds the coefficient of static friction which is 0.53 in this case (see Fig. 5). Figs. 5 and 6 show that higher fracture permeabilities relatively delay the time of seismic slip on the fault plane. This is because more time is taken for overpressure to build up on the fault/fracture plane and consequently cause shear

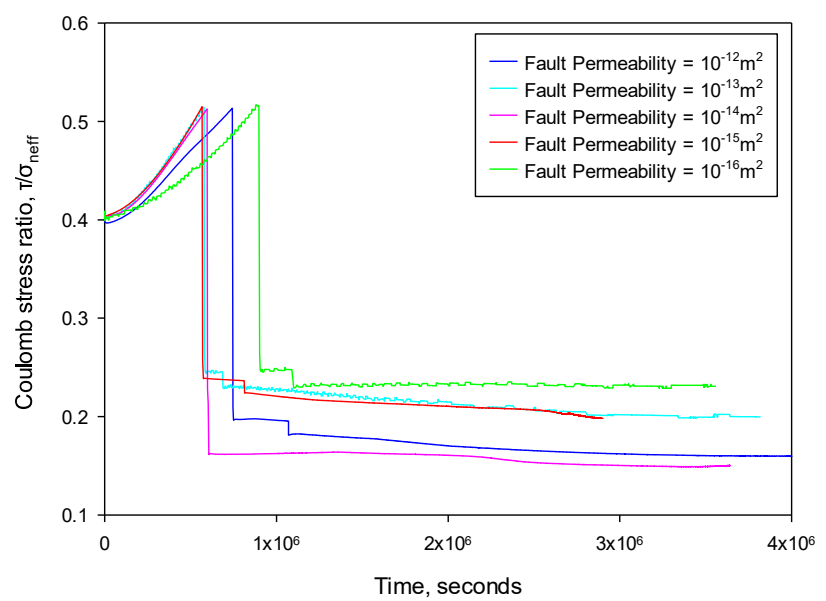

Fig. 5. Coulomb stress ratio evolution for the different fracture permeabilities.

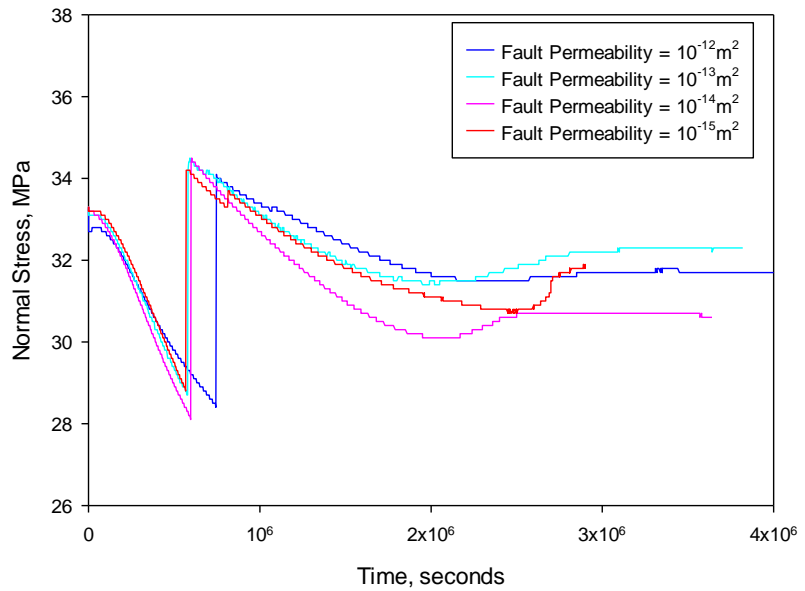

Fig. 6. Evolution of normal stresses for the different fracture permeabilities. 

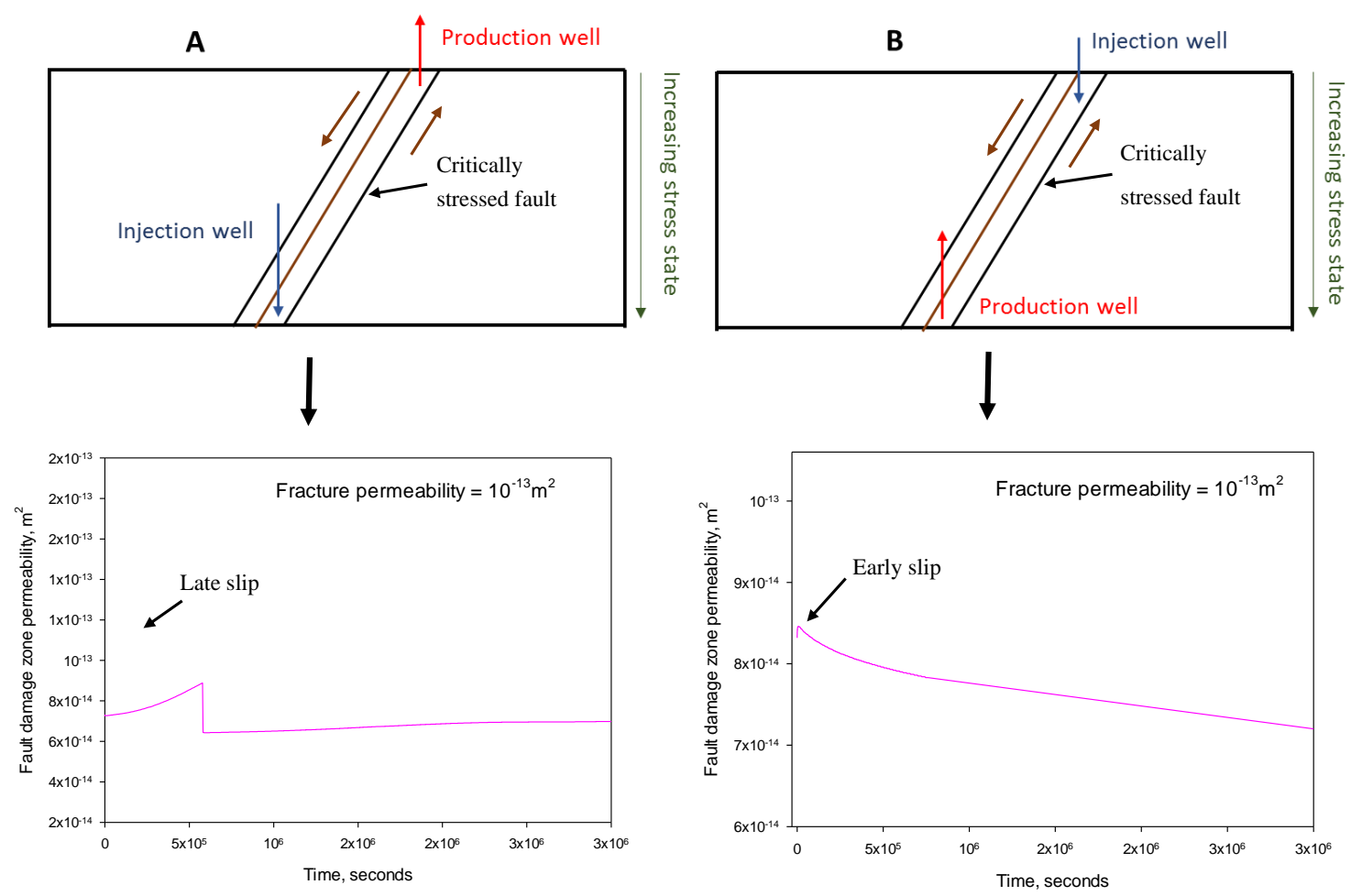

Fig. 7. Effects of the stress state at the injection well on permeability evolution and the time of slip. (a) The injection well is below the production well. (b) The injection well is above the production well.

failure. With higher fracture permeabilities, HM conditions regulate the time of slip more than thermal conditions. However, the least fracture permeability in the sensitivity analysis $\left(10^{-16} \mathrm{~m}^{2}\right)$ shows the latest time of slip on the fault plane. This delay is attributed to the shift of thermal sweep in the reservoir from advection mode to conduction mode, and because the rock matrix permeability is equally $10^{-16} \mathrm{~m}^{2}$ which is the same as the least fracture permeability used in this study for the fault damage zone.

\subsection{Location of the injection well}

The state of stress at the location of the injection well plays a role in determining the time of slip on the fault/fracture plane and hence the permeability evolution. The rate of fluid injection is kept constant at $10 \mathrm{~kg} / \mathrm{s}$ in both Figs. $7 \mathrm{a}$ and $7 \mathrm{~b}$. In Fig. $7 \mathrm{a}$, the injection well is placed below the withdrawal well along the fault and thus is under higher stress state. This reduces the rate of stress perturbation caused by fluid injection hence delaying the time of slip on the fault or fracture planes. In Fig. 7b where the injection well is placed above the withdrawal well, slip on the fault/fracture plane occurs earlier due to the lower stress state at the top end of the fault.

\subsection{Production rate and enthalpy conditions}

This study considers two scenarios labelled Case A and Case B (see Fig. 8a) to investigate changes in production (flow) rate, enthalpy (heat) conditions, and electrical power generation due to changes in the locations of the injection and the withdrawal wells along the fault zone. The state of stress at the upper end of the fault is lower than the state of stress at the lower end of the fault. The fluid injection rate was kept at $10 \mathrm{~kg} / \mathrm{s}$ throughout this investigation. Fracture spacing for testing these two scenarios was kept at $10 \mathrm{~m}$ while the fracture permeability of the fault damage zone was kept at $10^{-13} \mathrm{~m}^{2}$.

Fig. 8c indicates that the enthalpy conditions or water temperature in the two scenarios (Case A and Case B) are basically the same irrespective of the prevailing state of stress at locations of the injection and production wells along the fault zone. However, Figs. $8 \mathrm{~b}$ and $8 \mathrm{~d}$ indicate that production or flow rate, and electrical power generation are influenced by the stress state at the locations of the injection and production wells.

\subsection{Induced seismicity}

The magnitudes of the seismic events on the fault zone in the reservoir due to fluid injection are quantified based on the moment magnitude scale which gives a description of the strength of the seismic event. The moment magnitude scale describes the strength of the seismic event based on the event moment which is a measure of the energy released by the seismic slip on the fault plane (Kanamori and Abe, 1979). Eq. (6) relates the seismic moment to the moment magnitude (Shearer, 2009): 

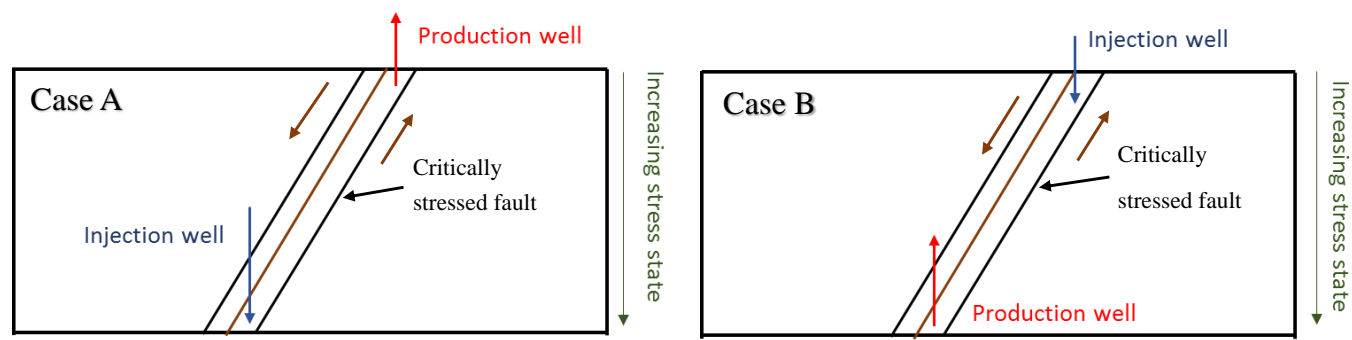

(a)

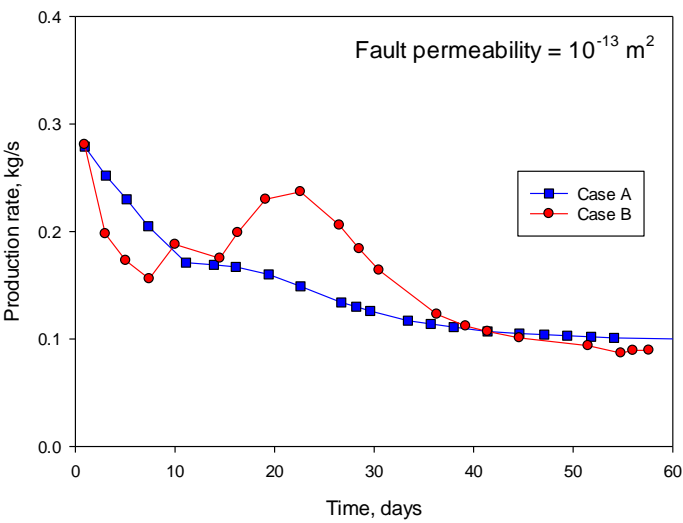

(b)

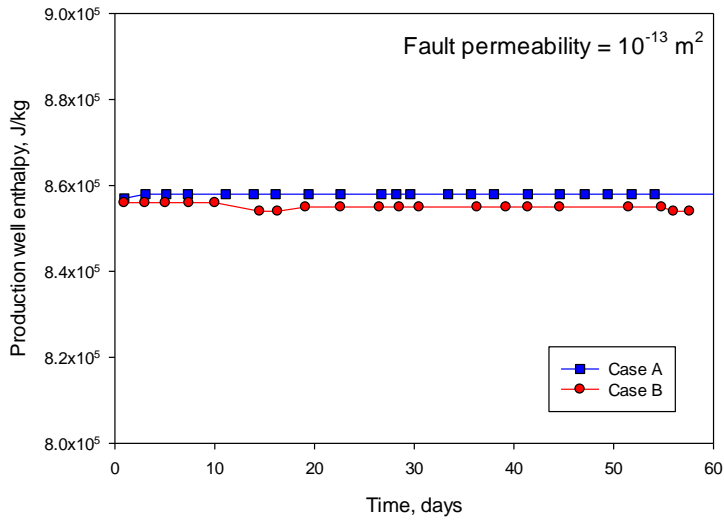

(c)

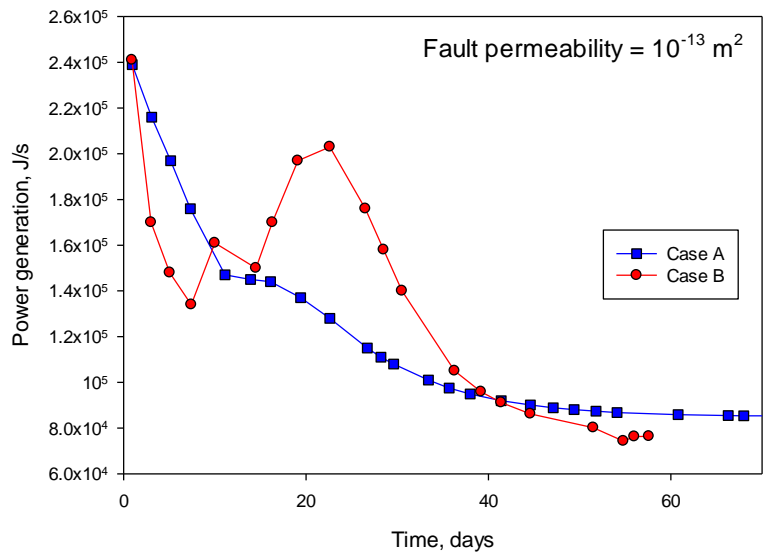

(d)

Fig. 8. Evolution of production rate and enthalpy conditions. (a) The two scenarios of well locations labelled Case A and Case B (b) Production rate or flow rate evolution for the two cases (c) Enthalpy or water temperature evolution for the two cases (d) Evolution of electrical power generation for the two cases.

where $M_{0}$ represents the seismic moment, $M_{w}$ represents the moment magnitude.

The seismic moment is given (Aki, 1967; Aki and Richards, 2009) as:

$$
\begin{aligned}
& M_{0}=\text { shear modulus } \times \text { rupture area } \times \text { slip distance } \\
& M_{0}=\mu L w d
\end{aligned}
$$

where $\mu$ is the shear modulus, $L$ is the fault length, $w$ is the fault rupture width, and $d$ is the slip distance. The induced seismicity on the fault/fracture planes for the different fracture permeabilities have moment magnitudes $\left(M_{w}\right)$ ranging from
2.0 to 2.2 . Figs. 9 and 10 show the distribution of the slip distances against the fault length.

Figs. 9 and 10 indicate that the slip distances on the fault/fracture planes due to fluid injection are quite small (in order of few centimetres). This gives rise to seismicity with maximum moment magnitude of 2.2.

\section{Discussion}

\subsection{THM effects on permeability evolution}

The fracture permeability sensitivity analysis shown in Figs. 4 and 7 demonstrates the effects of THM processes on 


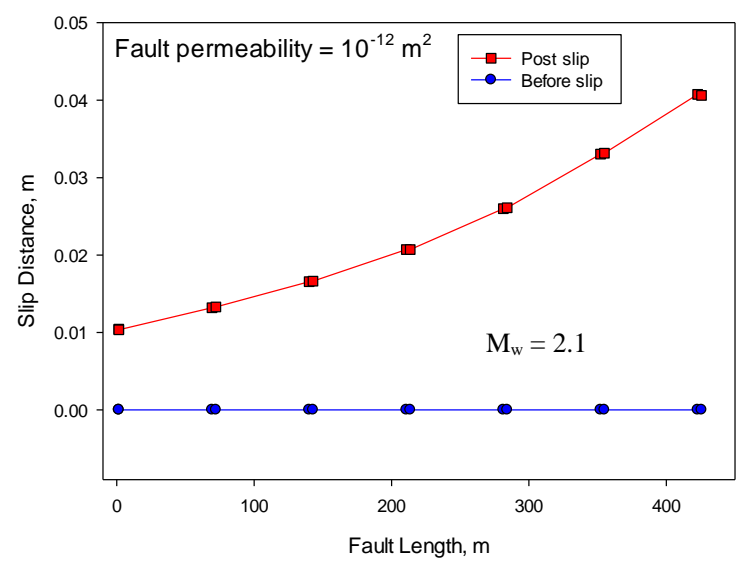

(a)

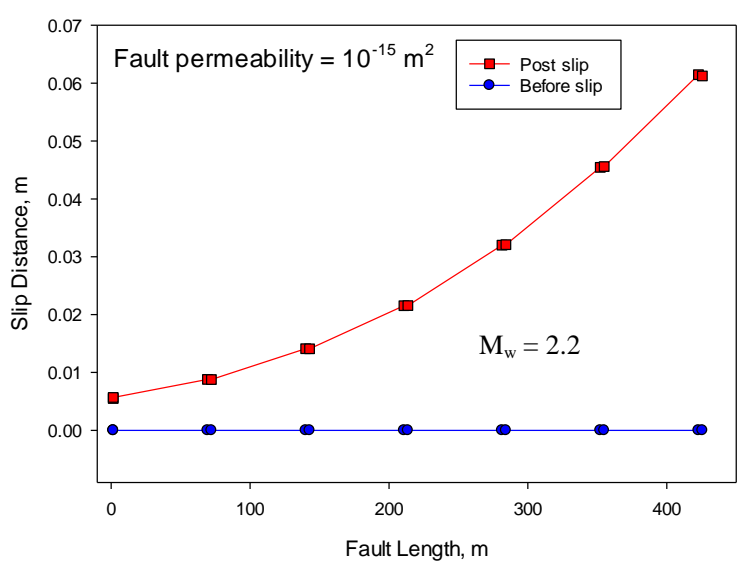

(c)

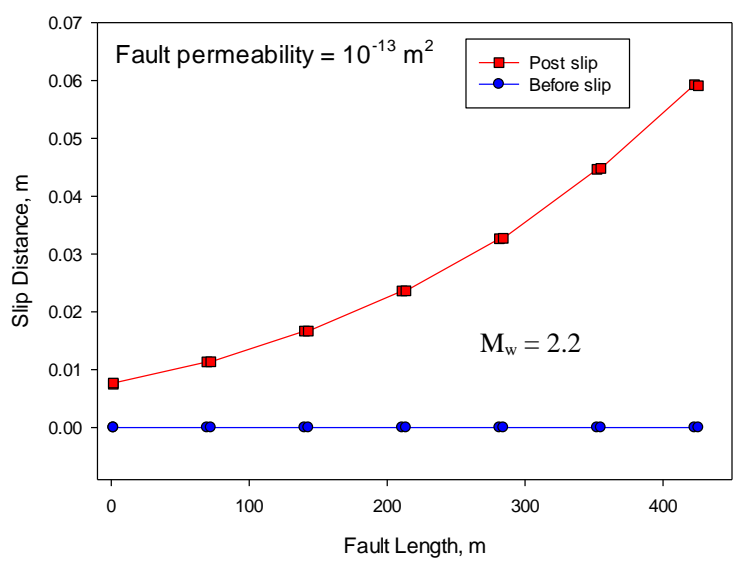

(b)

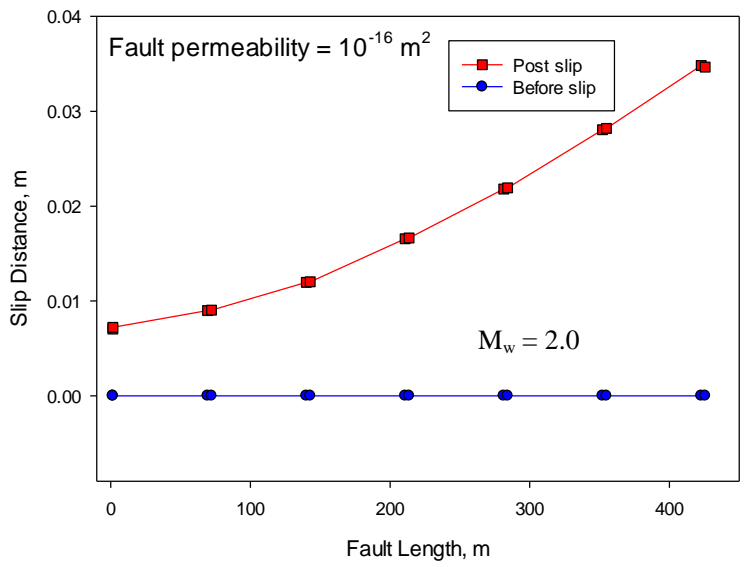

(d)

Fig. 9. Distribution of the fault slip distances before and after slip for the different fracture permeabilities $(\mathrm{a}-\mathrm{d})$.

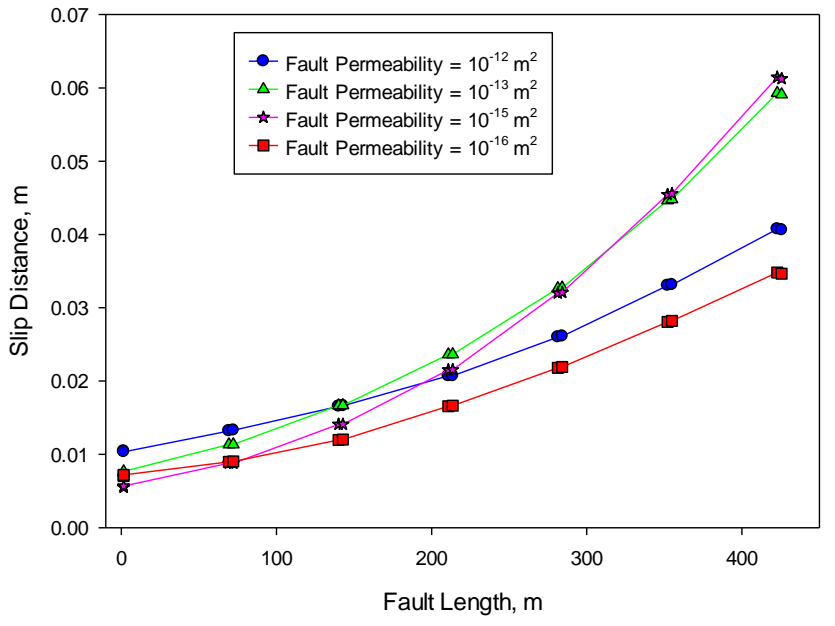

Fig. 10. Comparison of distribution of the fault slip distances for the different fracture permeabilities.

fracture permeability evolution. Specifically, the THM processes in the fractured porous media played a key role in determining the time of seismic slip and permeability change due to shear failure on the fault/fracture plane for the different fracture permeabilities (Figs. 4, 5, and 6). For the highest fracture permeability in Fig. $4\left(k=10^{-12} \mathrm{~m}^{2}\right)$, HM processes have dominant control on permeability evolution. The thermal sweep in the reservoir is dominated by advection over conduction as the high fracture permeability permitted higher velocity of fluid flow. The higher fracture permeability delays the time taken for overpressures to build up on the fault/fracture plane due to fluid injection thus delaying the time of slip on the fault plane. The build-up of pore pressures reduces the effective normal stress thereby increasing the shear stress component. The reduction of the effective normal stress plays a key role in the rheology of fractured porous media (Ranalli, 1995). The fault plane then slips when its frictional resistance is reached or exceeded by the shear stress component. In lower fracture permeabilities $\left(k=10^{-15}\right.$ to $\left.10^{-13} \mathrm{~m}^{2}\right)$ in Fig. 4, the build-up of overpressures is faster, thus causing the fault/fracture plane to shear or fail earlier. The fracture permeabilities also evolve or change with the shear failure on the fault/fracture plane. For the lowest fracture permeability in Fig. $4\left(k=10^{-16} \mathrm{~m}^{2}\right)$, thermal processes have dominating control on permeability evolution and time of slip. With reduction in fluid flow and HM effects, heat transfer in the reservoir is now dominated by conduction over advection. The 
temperature difference between the fault zone and the country rock becomes negligible. This lowest fault permeability is also the same as the country rock permeability $\left(10^{-16} \mathrm{~m}^{2}\right)$ used in this study. The shift of heat transfer mode from advection to conduction coupled with the uniform permeability and thermal state of both fault zone and country rock has delayed the time of slip for the lowest fracture permeability $\left(10^{-16} \mathrm{~m}^{2}\right)$. For the intermediate fracture permeabilities $\left(10^{-15}\right.$ to $\left.10^{-13} \mathrm{~m}^{2}\right)$, both HM and thermal processes combined to influence the permeability evolutions and the time of slip on the fault plane.

\subsection{The state of stress at the injection well}

The state of stress at the location of the injection well plays a role in determining the time of slip on the fault/fracture plane and hence the permeability evolution (Fig. 7). When the injection well is placed above the withdrawal well (upper end of the fault; see Fig. 7b), shear failure on the fault/fracture plane occurs earlier due to the lower state of stress at the top of the fault. On the other hand, when the injection well is placed at the lower end of the fault with higher state of stress (Fig. 7a), shear failure on the fault/fracture plane was delayed. The higher stress state at the lower end of the fault reduces the rate of stress perturbation due to fluid injection thus delaying the time of slip on the fault plane.

Fig. 8 demonstrates the effects of the state of stress at the locations of the injection and withdrawal wells along the fault on the flow (production) rate, enthalpy conditions or water temperature, and electrical power generation. For the two cases considered (Case A and Case B), the enthalpy conditions or water temperatures are primarily influenced by the prevailing temperatures and thermal gradients in the reservoir. Fig. 8c shows that the state of stress at the locations of the injection and production wells has little or no influence on the enthalpy conditions or water temperatures. However, the production or flow rate is influenced by the state of stress at the locations of the injection and production wells which in turn influences the electrical power generation (Figs. $8 \mathrm{~b}$ and $8 \mathrm{~d}$ ). This is interpreted to be a result of permeability change with shear failure since the state of stress at the injection well influences the timing of shear failure on the fault or fracture planes. The change in fracture permeability with shear failure which will occur at different times for Case A and Case B therefore influences the evolution of flow or production rate for the two cases and consequently influences the evolution of electrical power generation for the two cases.

\subsection{Induced seismicity}

The increased pore pressures in the fractured porous media due to hydraulic stimulation or fluid injection has the potential to perturb the state of stress and strain in the subsurface. This can cause distributed seismicity on the fault/fracture plane. Most of the man-made seismicity are however of low magnitude but may also be high if it involves reactivation on large faults that are weak (Gan and Elsworth, 2014a). Recorded earthquake magnitudes from this study due to fluid injection on the fault zone ranges from $M_{w}=2.0$ to $M_{w}=2.2$. Figs. 9 and 10 show that higher slip distances are distributed at the upper end of the fault zone. This is attributed to the lower stress state at the upper end of the fault zone. Generally, the higher the fracture permeability, the lower the slip distances and hence the lower the moment magnitude. This is due to the lower rate of accumulation of overpressures in higher fracture permeabilities due to fluid injection compared to lower fracture permeabilities where overpressures accumulate faster. This causes lower fracture permeabilities to slip earlier with higher slip distances and moment magnitudes. However the lowest fracture permeability for the damage zone in this study $(k=$ $10^{-16} \mathrm{~m}^{2}$ ) has a lower slip distance and moment magnitude. This has been attributed to the dominance of thermal processes over HM processes, in influencing permeability evolution and time of slip on the fault/fracture planes.

\section{Conclusions}

This study investigates the exploitation of the fault damage zone in the development of EGS. With the persistent problem of low porosity and permeability in deep EGS, the exploitation of a fault damage zone could play an important role in the commercial development of EGS. With the ubiquitous distribution of fractures in the fault damage zone and the presence of enhanced fracture apertures, permeability can be greatly enhanced thereby optimizing production. These enhanced fracture apertures of the fault damage zone have great influence on fracture permeability based on the cubic law for fluid flow in fractured porous media. The evolution of the fracture permeability is dependent on the evolution of fracture apertures under the effect of mechanical stress.

The fracture permeability sensitivity analysis of the fault damage zone demonstrates the effects of the THM processes on the evolution of fracture permeability and the time of slip or shear failure on the fault/fracture plane. For high fracture permeability $\left(10^{-12} \mathrm{~m}^{2}\right)$, HM processes have dominant control on permeability evolution and the time of slip on the fault plane. The mode of the thermal sweep in the reservoir is dominated by advection as the high fracture permeability permitted higher velocity of fluid flow. High fracture permeability delays the time taken for overpressures to build up on the fault/fracture plane due to fluid injection thus delaying the time of slip on the fault plane.

For low fracture permeability $\left(10^{-16} \mathrm{~m}^{2}\right)$, heat transfer processes has dominant control on permeability evolution and time of slip. With reduction in fluid flow and hydromechanical effects, heat transfer in the reservoir is dominated by conduction. For the intermediate fracture permeabilities $\left(10^{-15}\right.$ to $\left.10^{-13} \mathrm{~m}^{2}\right)$, both hydro-mechanical and thermal processes combined to influence the permeability evolutions and the time of slip on the fault plane. As the residence time for the cold fluids stay in the hot rocks, the low permeability in fault damage zone could allow more complete heat transfer by conduction. The induced thermal stress could unload fault stress state, by prompting the induce failure and reducing timing of slip. When the permeability is reduced to the magnitude of $10^{-16} \mathrm{~m}^{2}$, the increased communication between 
matrix and fault allows the dissipation of fluid to the host rocks and reduce pore pressure elevation gradient.

Not only the permeability of fault zone affects the timing of slip, but also the volumetric ratio of damage zones over the entire domain will also have impact on the heat transfer and the associated slip results. In this work, the concept for direct injection inside fault is to evaluate the influence of localized heat transfer inside fault in triggering fault. Consequently, it could expect that when the fault is significant larger $(\sim 400$ $\mathrm{m}$ wide) (United Downs Deep Geothermal project), it will take longer time to build up pressure, and large potential in dissipating pressure to the surrounding rock, depending on the permeability of host rocks. It will be valuable to investigate the sustainable period and injection rate to circulate fluids along fault, to maximize the heat transfer energy while minimizing the potential of fault instability.

Also, the state of stress at the location of the injection well plays a role in determining the time of slip on the fault/fracture plane and hence the permeability evolution. When the injection well is placed above the withdrawal well (upper end of the fault), shear failure on the fault/fracture plane occurs earlier due to the lower stress state at the top of the fault. When the injection well is placed at the lower end of the fault (with higher stress state), shear failure on the fault/fracture plane was delayed. The evolution of production or flow rate is also influenced by the state of stress at the locations of the injection and production wells which in turn influences the evolution of electrical power generation. This has been attributed to different timing of permeability change with shear failure since the state of stress at the injection well influences the timing of shear failure on the fault or fracture planes. The change in fracture permeability with shear failure therefore influences the evolution of flow or production rate depending on the stress state at the injection well which consequently influences the evolution of electrical power generation.

The elevated pore pressures in the fractured porous media due to hydraulic stimulation or fluid injection has the potential to perturb the state of stress and strain in enhanced geothermal reservoirs thus causing distributed seismicity on the fault/fracture planes. The seismicity from the permeability sensitivity analysis all have moment magnitudes that are below 2.5.

\section{Acknowledgement}

I would like to thank my project supervisor Dr. Quan Gan for his guidance and supervision throughout the project. I also thank Waheed Akande (PhD Student) for his support during the project. I am grateful to the Petroleum Technology Development Fund (PTDF) for funding my master's programme.

\section{Conflict of interest}

The authors declare no competing interest.

Open Access This article, published at Ausasia Science and Technology Press on behalf of the Division of Porous Flow, Hubei Province Society of Rock Mechanics and Engineering, is distributed under the terms and conditions of the Creative Commons Attribution (CC BY-NC-ND) license, which permits unrestricted use, distribution, and reproduction in any medium, provided the original work is properly cited.

\section{References}

Aki, K. Scaling law of seismic spectrum. J. Geophys. Res. 1967, 72(4): 1217-1231.

Aki, K., Richards, P.G. Quantitative Seismology, Second Edition. Virginia, USA, University Science Books, 2009.

Boutareaud, S., Wibberley, C.A.J., Fabbri, O., et al. Permeability structure and co-seismic thermal pressurization on fault branches: Insights from the Usukidani fault, Japan. Geol. Soc. London, Spec. Publ. 2008, 299(1): 341-361.

Byerlee, J. Friction of rocks, In Rock friction and earthquake prediction, edited by J.D. Byerlee, and M. Wyss, Birkhäuser, Basel, pp. 615-626, 1978.

Caine, J.S., Evans, J.P., Forster, C.B. Fault zone architecture and permeability structure. Geology 1996, 24(11): 10251028.

Cappa, F., Rutqvist, J. Modeling of coupled deformation and permeability evolution during fault reactivation induced by deep underground injection of $\mathrm{CO}_{2}$. Int. J. Greenhouse Gas Control 2011, 5(2): 336-346.

Cappa, F., Rutqvist, J. Seismic rupture and ground accelerations induced by $\mathrm{CO}_{2}$ injection in the shallow crust. Geophys. J. Int. 2012, 190(3): 1784-1789.

Chester, F.M., Logan, J.M. Composite planar fabric of gouge from the Punchbowl Fault, California. J. Struct. Geol. 1987, 9(5-6): 621-634.

Cox, S.F. Faulting processes at high fluid pressures: An example of fault valve behaviour from the Wattle Gully Fault, Victoria, Australia. J. Geophys. Res. 1995, 100(B7): 12841-12859.

Cummings, R.G. Nunn, S.C. An economic analysis of the hot dry rock geothermal energy resource. Resour. Energy 1978, 1(2): 109-123.

Duchane, D., Brown, D. Hot dry rock (HDR) geothermal energy research and development at Fenton Hill, New Mexico. GHC Bull. 2002, 23(4): 13-19.

Ellsworth, W.L. Injection-induced earthquakes. Science 2013, 341(6142): 1225942.

Evans, J.P., Forster, C.B., Goddard, J.V. Permeability of faultrelated rocks, and implications for hydraulic structure of fault zones. J. Struct. Geol. 1997, 19(11): 1393-1404.

Faulkner, D., Jackson, C., Lunn, R., et al. A review of recent developments concerning the structure, mechanics and fluid flow properties of fault zones. J. Struct. Geol. 2010, 32(11): 1557-1575.

Faulkner, D.R., Lewis, A.C., Rutter, E.H. On the internal structure and mechanics of large strike-slip fault zones: Field observations of the Carboneras fault in southeastern Spain. Tectonophysics 2003, 367(3-4): 235-251.

Fomin, S., Zing, Z., Hashida, T. The effect of thermal, chemical, hydrological, and mechanical factors on water/rock interaction in HDR geothermal systems. Elsevier Geo-Engineering Book Series 2004, 2: 649654.

Gan, Q., Elsworth, D. Analysis of fluid injection-induced fault reactivation and seismic slip in geothermal reservoirs. J. Geophys. Res. 2014a, 119(4): 3340-3353.

Gan, Q., Elsworth, D. Thermal drawdown and late-stage 
seismic-slip fault reactivation in enhanced geothermal reservoirs, J. Geophys. Res. 2014b, 119(12): 8936-8949.

Gan, Q. Elsworth, D. A continuum model for coupled stress and fluid flow in discrete fracture networks. Geomech. Geophys. Geo-Energy Geo-Resour. 2016a, 2: 43-61.

Gan, Q., Elsworth, D. Production optimization in fractured geothermal reservoirs by coupled discrete fracture network modelling. Geothermics 2016b, 62: 131-142.

Geothermal Engineering Ltd 2019, United downs deep geothermal project, accessed 27 June 2019.

Glassley, W.E. Geothermal Energy: Renewable Energy and The Environment (Second Edition). CRC press, 2015.

Ijeje, J.J., Gan, Q., Cai, J. Influence of permeability anisotropy on heat transfer and permeability evolution in geothermal reservoir. Adv. Geo-Energy Res. 2019, 3(1): 43-51.

Jaeger, J.C., Cook, N.G.W., Zimmerman, R.W. Fundamentals of Rock Mechanics, Fourth Edition. UK, Blackwell Publishing, 2007

Kanamori, H., Abe, K. Reevaluation of the turn-of-the-century seismicity peak. J. Geophys. Res. 1979, 84(11): 61316139.

Levandowski, W., Weingarten, M., Walsh, R. Geomechanical sensitivities of injection-induced earthquakes. Geophys. Res. Lett. 2018, 45(17): 8958-8965.

Li, W., Yost, K. Sousa, R. Heat transfer between fluid flow and fractured rocks. GRC Trans. 2013, 37: 165-171.

McNamara, D.E., Benz, H.M., Herrmann, R.B., et al. Earthquake hypocenters and focal mechanisms in central Oklahoma reveal a complex system of reactivated subsurface strike-slip faulting. Geophys. Res. Lett. 2015, 42(8): 2742-2749.

Min, K.B., Rutqvist, J., Elsworth, D. Chemically and mechanically mediated influences on the transport and mechanical characteristics of rock fractures. Int. J. Rock Mech. Min. 2009, 46(1): 80-89.

Mitchell, T., Faulkner, D. The nature and origin of off-fault damage surrounding strike-slip fault zones with a wide range of displacements: A field study from the Atacama fault system, northern Chile. J. Struct. Geol. 2009, 31(8): 802-816.

Moeck, I., Kwiatek, G., Zimmermann, G. Slip tendency analysis, fault reactivation potential and induced seismicity in a deep geothermal reservoir. J. Struct. Geol. 2009, 31(10): 1174-1182.

Morris, A., Ferrill, D.A., Henderson, D.B. Slip-tendency analysis and fault reactivation. Geology 1996, 24(3): 275-278.

Pandey, S.N., Chaudhuri, A., Kelkar, S. A coupled thermohydro-mechanical modelling of fracture aperture alteration and reservoir deformation during heat extraction from a geothermal reservoir. Geothermics 2017, 65: 1731.

Pruess, K. Heat transfer in fractured geothermal reservoirs with boiling. Water Resour. Res. 1983, 19(1): 201-208.

Ranalli, G. Rheology of The Earth, Second Edition. New
York, USA, Chapman and Hall, 1995.

REN21 2019, Renewables 2019 global status report, accessed 27 June 2019.

Rubey, W.W., Hubbert, M.K. Role of fluid pressure in mechanics of overthrust faulting. Geol. Soc. Am. Bull. 1959, 76(4): 469-474.

Rutqvist, J., Oldenburg, C. Analysis of cause and mechanism for injection-induced seismicity at the Geysers Geothermal Field. GRC Trans. 2007, 31: 441-445.

Rutqvist, J., Wu, Y., Tsang, C.F., et al. A modeling approach for analysis of coupled multiphase fluid flow, heat transfer, and deformation in fractured porous rock, Int. J. Rock Mech. Min. Sci. 2002, 39(4): 429-442.

Salimzadeh, S., Paluszny, A., Nick, H.M., et al. A threedimensional coupled thermo-hydro-mechanical model for deformable fractured geothermal systems. Geothermics 2018, 71: 212-224.

Scholz, C.H. The Mechanics of Earthquakes and Faulting, 3rd Edition. Cambridge, UK, Cambridge University Press, 2019.

Shearer, P.M. Introduction to Aeismology, Aecond Edition. Cambridge, UK, Cambridge University Press, 2009.

Taron, J., Elsworth, D. Thermal-hydrologic-mechanicalchemical processes in the evolution of engineered geothermal reservoirs. Int. J. Rock Mech. Min. Sci. 2009, 46(5): 855-864.

Taron, J., Elsworth, D. Coupled mechanical and chemical processes in engineered geothermal reservoirs with dynamic permeability. Int. J. Rock Mech. Min. 2010, 47(8): 1339-1348.

Taron, J., Elsworth, D., Min, K.B. Numerical simulation of thermal-hydrologic-mechanical-chemical processes in deformable, fractured porous media. Int. J. Rock Mech. Min. Sci. 2009, 46(5): 842-854.

Tester, J.W., Anderson, B.J., Batchelor, A.S., et al. The future of geothermal energy: Impact of Enhanced Geothermal Systems (EGS) on the United States in the 21st century. Massachusetts Institute of Technology, 2006.

Tester, J.W., Brown, D.W., Potter, R.M. Hot Dry Rock Geothermal Energy-A New Energy Agenda for The 21st Century. USA, Los Alamos National Laboratory report, 1989.

Turcotte, D.L., Schubert, G. Geodynamics, Third Edition. Cambridge, UK, Cambridge University Press, 2014.

Witherspoon, P.A., Wang, J.S.Y., Iwai, K., et al. Validity of cubic law for fluid flow in a deformable rock fracture. Water Resour. Res. 1980, 16(6): 1016-1024.

$\mathrm{Xu}, \mathrm{T}$., Sonnenthal, E., Spycher, N. TOUGHREACT user's guide: A simulation program for non-isothermal multiphase reactive geochemical transport in variable saturated geologic media. Lawrence Berkeley National Laboratory, 2004.

Zoback, M.D. Reservoir Geomechanics. Cambridge, UK, Cambridge University Press, 2007. 